\title{
EXPERIMENTAL INVESTIGATION OF THE SHEAR ANGLE VARIATION DURING ORTHOGONAL CUTTING
}

\author{
Szabolcs Berezvai, Tamas G. Molnar, Daniel Bachrathy, Gabor Stepan
}

Budapest University of Technology and Economics, Department of Applied Mechanics, Muegyetem rkp. 5., Budapest, 1111 Hungary. E-mail: berezvai@mm.bme.hu

\section{Introduction}

In this contribution, we investigate the variation of the shear angle during orthogonal cutting processes illustrated in Fig. 1. In orthogonal cutting, the material in front of the cutting edge is sheared over a primary shear zone that is approximated by the shear plane located at shear angle $\Phi$. The shear angle determines the magnitude of the cutting force acting on the tool and the coefficients of theoretical cutting force models. An important application of the cutting force models is the investigation of machine tool vibrations [1-3], where the cutting force coefficients have significant effect on the dynamics of metal cutting. Consequently, modelling and measuring the shear angle is important in terms of developing accurate cutting force expressions to investigate the dynamics of cutting processes.

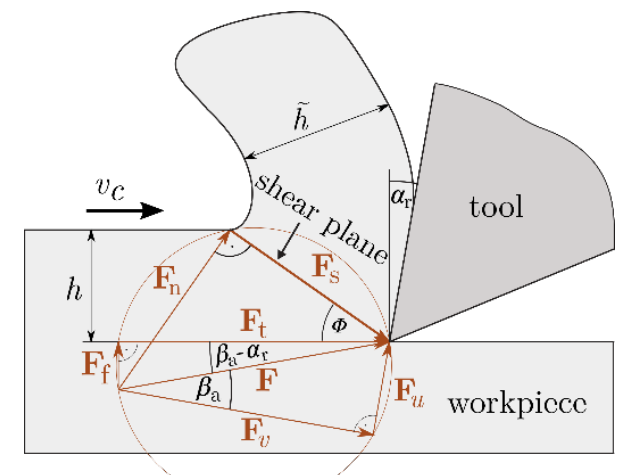

Fig. 1. The Merchant's model of cutting forces

\section{Shear angle models}

The most well-known approach of modelling cutting forces is Merchant's circle [4] illustrated in Fig. 1. In this model, the cutting force component $\mathbf{F}_{\mathrm{s}}$ aligned with the shear plane is calculated as the product of the yield shear stress and the shear plane area, from which other components of the cutting force $\mathbf{F}$ can also be determined based on the rake angle $\alpha_{\mathrm{r}}$ and the average friction angle $\beta_{\mathrm{a}}$. Since the shear plane area depends on the shear angle, the coefficients of theoretical cutting expressions are in fact functions of the shear angle. The most well-known shear angle models are the maximum shear stress principle, which states that the angle of the cutting force vector and the shear plane is 45 degrees; and the minimum energy principle, which assumes that the power of the cutting force is minimal and determines the shear angle accordingly [4]. These models are typically used to describe stationary cutting processes where the uncut chip thickness $h$ is constant. However, during cutting the chip thickness may vary in time, especially in the case of machine tool vibrations.

\section{Experimental layout}

The goal of this contribution is to determine the shear angle experimentally during non-stationary orthogonal cutting of a single aluminum rib with thickness of $w=2 \mathrm{~mm}$, and to investigate the relationship between the chip thickness, the cutting force and the shear angle using high-speed camera recordings [5].

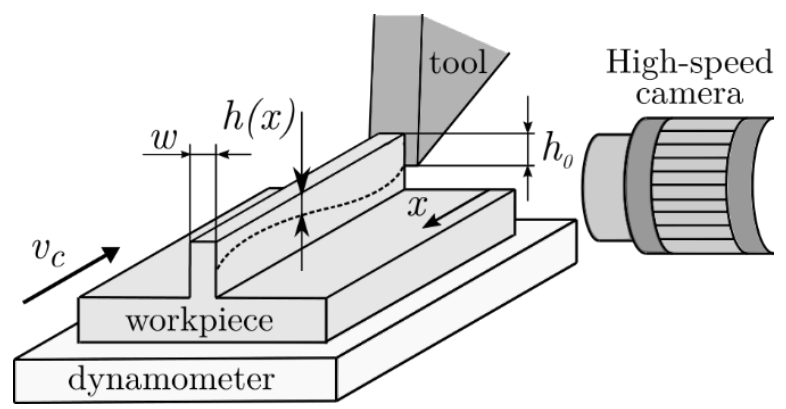

Fig. 2. The schematics of the experimental layout

As the measurement layout shows (see Fig. 2), the workpiece was placed on a KISTLER 9129 AA multicomponent dynamometer, while the chip formation process was recorded by Photron SA5 high-speed camera with 10,000 fps. The chip thickness was prescribed according to the sinusoidal function $h(x)=h_{0}+h_{A} \sin (2 \pi x / \lambda)$, where $h_{0}$ is the average chip thickness, $h_{A}$ the amplitude and $\lambda$ the wavelength. 


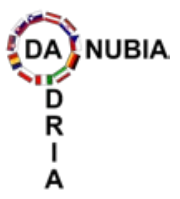

34th Danubia-Adria Symposium on Advances in Experimental Mechanics

University of Trieste, Italy, 2017
The geometry of the tool can be characterized by rake angle of $\alpha_{\mathrm{r}}=15^{\circ}$ and flank angle of $\alpha_{\mathrm{f}}=10^{\circ}$. The cutting speed $v_{c}$ was set between 5,000 and $10,000 \mathrm{~mm} / \mathrm{min}$. Based on the highspeed camera recordings the shear-layer could be detected using displacement-based image processing techniques.

\section{Results}

The results of the experimental investigation can be summarized on Figs. 3-4., which show the detected shear layer, and the variation of the cutting forces during time-varying orthogonal cutting, respectively. It can be concluded, that the image processing method is able to detect adequately the shear plane and angle. Moreover, the comparison of the variation of the shear angle with the cutting forces helps to understand the dynamics of non-stationary cutting processes with time-varying chip thickness.

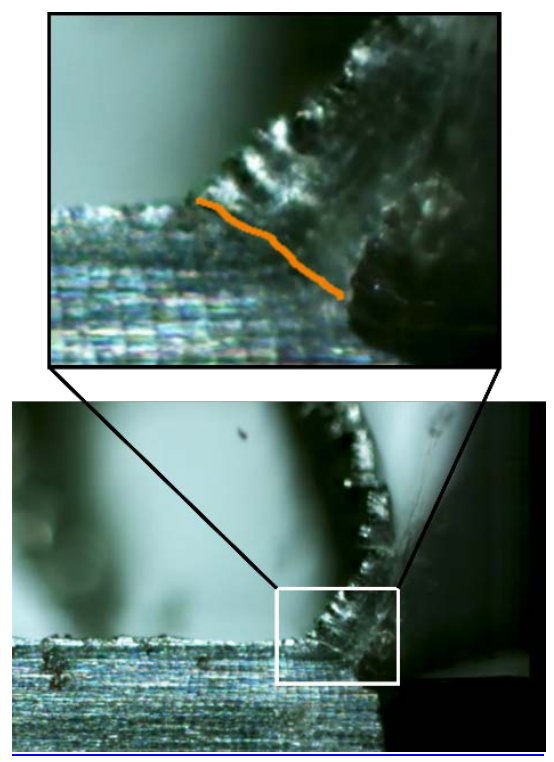

Fig. 3. The detected shear layer in case of sinusoidal cutting process with $h_{0}=0.25 \mathrm{~mm}, h_{A}=0.1 \mathrm{~mm}$, $\lambda=10 \mathrm{~mm}$ and $v_{c}=5000 \mathrm{~mm} / \mathrm{min}$

\section{Acknowledgements}

This research has been supported by the ÚNKP16-3-I. New National Excellence Program of the Ministry of Human Capacities, Hungary. The research leading to these results has received funding from the European Research Council under the European Union's Seventh Framework Programme (FP/2007-2013) / ERC Advanced Grant Agreement n. 340889.

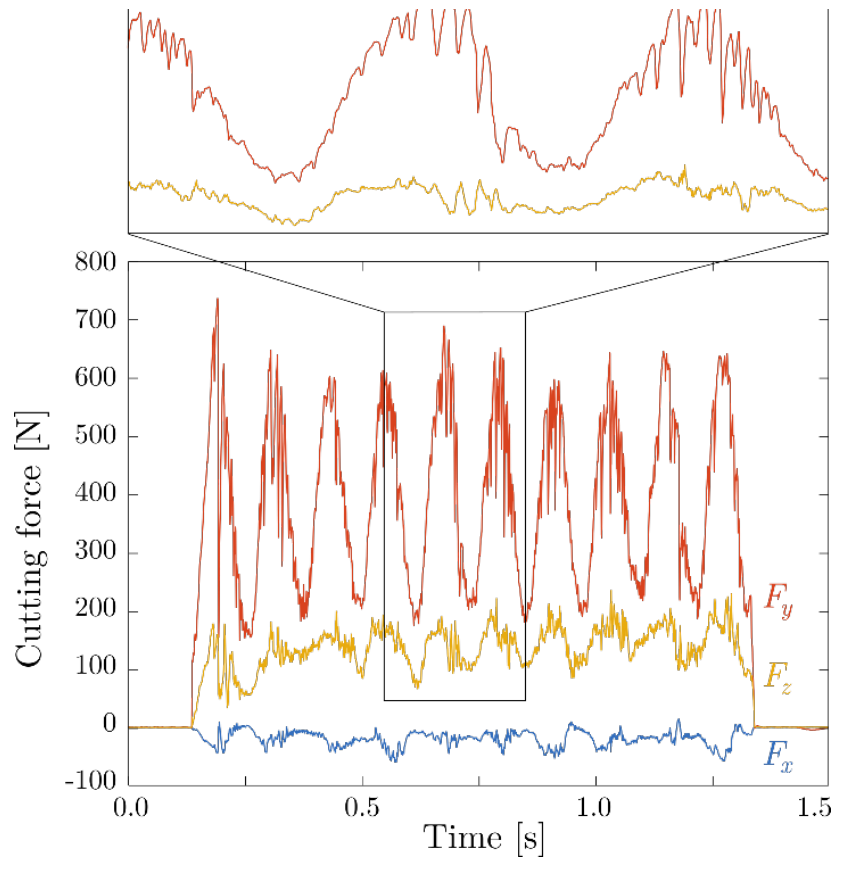

Fig. 4. The variation of the cutting force during sinusoidal cutting process with $h_{0}=0.2 \mathrm{~mm}$, $h_{A}=0.1 \mathrm{~mm}, \lambda=10 \mathrm{~mm}$ and $v_{c}=5000 \mathrm{~mm} / \mathrm{min}$

\section{References}

[1] S. A. Tobias and W. Fishwick, Theory of regenerative machine tool chatter, The Engineer, 205(7), 1958, pp.199-203, 238-239.

[2] J. Tlusty and M. Polacek, The stability of the machine tool against self-excited vibration in machining, ASME Production Engineering Research Conference, Pittsburgh, 1963, pp. 454-465.

[3] E. Budak and Y. Altintas, Analytical Prediction of Chatter Stability in Milling Part I: General Formulation, ASME Journal of Dynamic Systems, Measurement, and Control 120, 1998, pp. 22-30.

[4] Y. Altintas, Manufacturing Automation Metal Cutting Mechanics, Machine Tool Vibrations and CNC Design, Second Edition, Cambridge University Press, Cambridge, 2012.

[5] Y. Guo, W.D. Compton and S. Chandrasekar, In situ analysis of flow dynamics and deformation fields in cutting and sliding of metals, Proceedings of the Royal Society A, 471, 2015. 